\title{
Phenotypic Characterization and Serotypes Identification of CSF isolates in Acute Bacterial Meningitis
}

\author{
Birhanemeskel Tegene $^{1, *}$, Kassahun Denekew ${ }^{2}$, Gashaw Mesele $^{3}$ \\ ${ }^{1}$ Department of Medical Microbiology, college of Medicine and Health Sciences, University of Gondar, Ethiopia \\ ${ }^{2}$ Department of Pediatrics and Child Health, college of Medicine and Health Sciences, University of Gondar, Ethiopia \\ ${ }^{3}$ Department of Surgery, Faculty of Medicine and Health Sciences, University of Gondar, Ethiopia \\ *Corresponding author: meskelbirehane@gmail.com
}

\begin{abstract}
Background and Aim: Bacterial meningitis is a fatal disabling disease which needs prompt antibiotic management. As it causes a significant morbidity and mortality throughout the world, every developing country should have accurate information regarding the common etiological agents in bacterial meningitis cases. In the present study, we have serotyped the obtained agents in order to predict the usefulness of existing vaccines against bacterial meningitis. Materials and Methods: Two thousand nineteen cerebrospinal fluid (CSF) samples were obtained prospectively from suspected meningitis from January 2011 to July 2013 out of which 76 cases were approved by cytological, microbiological, molecular, and biochemical analysis as per the standard techniques. The isolated bacteria were serotyped to determine the predominant strain. Results: On the whole, 2019 CSF samples were collected, and bacterial etiology was isolated in 76 cases; S. pneumoniae in $31.5 \%$, N. meningitides in $18.4 \%$, and $\mathrm{H}$. influenza in $10.5 \%$ of culture positive samples. Gram stained smears were positive in 63 samples. Among pneumococcal meningitis the most common serotype was 1 , (29 \%), followed by $19 \mathrm{~F},(25 \%), 18 \mathrm{~F},(8.3 \%), 6$, $(16.6 \%), 14,(12.5 \%)$, and $20(8.3 \%)$. Out of the N. meningitidis positive CSF samples, $35.7 \%, 21.4 \%$, and $35.7 \%$, belonged to serogroups A, C, and W-135, respectively, and one non-groupable isolate were involved as S. pneumoniae meningitis. In the H. influenzae group only serotype b (87.5\%), and untypable, $1,(7.5 \%)$ cases have been identified. Only $17,(0.8 \%)$ soluble antigens were detected from culture negative CSF samples. High protein and low sugar levels associated well with the features of ABM. The mean sugar and protein level in the CSF samples were $22.3 \pm 9.8 \mathrm{mg} / \mathrm{dl}, 85.3 \pm 51.29 \mathrm{mg} / \mathrm{dl}$, respectively. Conclusions: The isolation rate of bacteria causing meningitis is $3.8 \%$. Out of the total pneumococcal serotypes three of them were not included in the current vaccine in Ethiopia. Unusual findings and high a proportion of serogroup W-135 meningococci are observed in our study area The role of clinical presentations, routine CSF analysis in the rapid diagnosis of acute bacterial meningitis in cases of negative gram stained smears and a good knowledge of the bacterial epidemiology of meningitis can serve as a guide to start a rapid treatment as early as possible. Recommendation: the result of this study can be used to improve the existing vaccines to cover the detected serotypes and consequently reduce the incidence of bacterial meningitis.
\end{abstract}

Keywords: acute bacterial meningitis neisseria meningitids, streptococcus pneumoniae, huemophilus and latex agglutination test

Cite This Article: Birhanemeskel Tegene, Kassahun Denekew, and Gashaw Mesele, "Phenotypic Characterization and Serotypes Identification of CSF isolates in Acute Bacterial Meningitis." American Journal of Infectious Diseases and Microbiology, vol. 5, no. 3 (2017): 100-105. doi: 10.12691/ajidm-5-3-1.

\section{Introduction}

Bacterial meningitis is potentially one of the most serious infections occurring in infants and older children and is associated with a high incidence of acute complications and risk of long-term morbidity. [1,2] It is one of the relatively common diseases of children in that, if it is not diagnosed urgently and curetting timely would be along with resulting fatality and many troubles like blindness, deafness hydrocephalus, neurologic disorders, paraplegic and general paralysis, mental retardation, and many other cases $[3,4]$. Despite great advances in antimicrobial therapy, pediatric life support measures and early detection of risk factors, bacterial sepsis and meningitis continue to be a major cause of morbidity and mortality in newborns, particularly in low-birth-weight infants [6].

The relative frequency of the isolation of various bacterial species as causes of meningitis varies with age, and among geographical regions. [5,7] About $80 \%$ of all cases of bacterial meningitis are caused by $S$. pneumoniae, Haemophilus influenza type b (Hib), and Neisseria 
meningitidis [8]. Group B streptococci (GBS) and Gramnegative enteric bacilli are the main causative agents of this cerebral inflammation in neonates $[9,11]$.

In many African countries, including Ethiopia, which lie within the meningitis belt, epidemic cases of acute bacterial meningitis caused by different subtypes of $N$. meningitidis have been reported [10,12]. Epidemics were also reported in Ethiopia between 2001 and 2003. The numbers of cases in each year from 2000 to 2003 were $855,6,266,2,329$, and 3,540, respectively, and the case fatality rates (CFRs) in the same period were 2.2, 5.0, 5.0 and 4.7, respectively [12]. Haemophilus influenza was the most invasive type of meningitides before the introduction of the new highly effective conjugated Hib vaccines. Streptococcus pneumoniae is one of the other common agents of meningitis in Ethiopia. Having considered that no research has been conducted on the serotypes of etiologic agents of meningitis in our tertiary care hospital, this study set out to address this issue.

\section{Materials and Methods}

This study, which was approved and permitted from Institutional Ethics Committee and Hospital administrator respectively, was conducted in the Department of Microbiology Pediatrics, and hospital laboratory. Between January, 2011 and July, 2013. Two thousand and nineteen suspected cases of acute bacterial meningitis, who were admitted to various wards of our hospital, were included in this study. The patients were assessed for acute meningitis, based on the following clinical signs and symptoms: headache (not relieved by analgesics), low or high-grade fever of acute onset which lasted for several days, nausea or projectile vomiting (not relieved by antiemetics), neck rigidity, hypotension, skin rash, consciousness, mental apathy, etc. Cases of due to structural defects of the central nervous system were excluded from the study group demographic and clinical data were recorded in predefined case record forms and only one representative CSF sample from every patient was included. Collection was performed aseptically on the patients in sterile screw capped containers.

In total, 2019 samples of CSF were initially subjected to a naked-eye examination for macroscopic appearance, and they were processed further for cell counts, biochemical analysis, gram staining, culture, antigen detection by latex agglutination test (LAT), and quelling reaction. A $3-5 \mathrm{ml}$ of CSF specimens were obtained and transported to the microbiology laboratory within 30 minutes with all proposed precautions, if delay for a few hours was unavoidable, the specimen was kept in an incubator at $37^{\circ} \mathrm{C}$. A portion of the sample was inoculated on blood agar, chocolate agar, and McConkey agar by standard loop method. The culture plate was incubated under $5-10 \% \mathrm{CO}_{2}$ at $37^{\circ} \mathrm{C}$ for $18-24$ hours. The remaining CSF sample was transported to hematology laboratory and clinical chemistry laboratory for cytological and biochemical analysis respectively.

The isolated bacteria were identified and interpreted using conventional techniques including Gram staining, growth in differential media, the morphology of the colonies and standard biochemical tests including oxidase, catalase, optochin test and bile solubility, TSI, IMVIC, SIM and Urea [13]. In order to investigate soluble antigens in CSF specimen, soluble antigens of, bacteria meningitides were identified using commercially available kit from Tulip Diagnostics Pvt. Ltd, India. Serotyping of the isolate was performed using the capsular swelling procedure (the quelling reaction) using antisera (Statens Serum Institute, Copenhagen, Denmark) according to the manufacturer's protocol [25].

Routine total cell counts were obtained for each sample by using a standard hematology analyzer (Sysmex kx-21N). Protein and sugar levels in the samples were estimated by using a standard, semi-automated biochemistry analyzer (Mendery200). CSF sediment smears were gram stained and they were examined for the presence of microbes, if any.

Statistical analysis of all variables were expressed as mean \pm SD. chi-square test was used for statistical analysis SPSS version 20. P values less than 0.05 were considered as statistically significant.

\section{Result}

Demographic data of the studied participant. Of the 2019 patients who were clinically suspected of having acute bacterial meningitis, 1147 (56.8\%) were males. The most common age group of presentation was above 11 years $(36.9 \%)$, while $63.1 \%$ patients were $\leq 11$ years of age. Children under one year of age (14 of 73; 23.7\%) had the highest incidence of meningitis in the study population and the male-to-female ratio was $1.4: 1$. The age distribution was from 1 month up to 54 years old with the mean age of 13 [Table 1].

Clinical presentations of the studied participant. The patients showed variable symptomatologies which ranged from fever (99.7\%), headache (98\%), nausea (81\%), projectile vomiting $(85 \%)$, neck rigidity $(89.2 \%)$, consciousness $(36.2 \%)$, seizures $(2 \%)$, hypotension $(4 \%)$ and skin rash $(27 \%)$. were diagnosed in 76 patients admitted to university hospitals during 30 months [Table 2].

Table 1. Demographic data of bacterial meningitis in the studied population at University of Gondar Teaching Hospital, January 2011 - August 2013

\begin{tabular}{|c|c|c|c|c|}
\hline & \multirow[b]{2}{*}{ Character } & \multicolumn{2}{|c|}{ Result } & \multirow[b]{2}{*}{ P. value } \\
\hline & & Positive & Negative & \\
\hline \multirow{2}{*}{ Sex } & Male & 43 & 1004 & \multirow{2}{*}{0.401} \\
\hline & Female & 33 & 939 & \\
\hline \multirow{4}{*}{ Age } & $1-28$ & 9 & 64 & \multirow{4}{*}{0.001} \\
\hline & 1-12 month & 14 & 59 & \\
\hline & 1-11 year & 25 & 96 & \\
\hline & $\mathrm{Y}>11$ year & 28 & 1724 & \\
\hline \multirow{3}{*}{ year } & 2011 & 26 & 449 & \multirow{3}{*}{0.059} \\
\hline & 2012 & 27 & 714 & \\
\hline & 2013 & 23 & 780 & \\
\hline \multirow{2}{*}{ Area } & Urbane & 14 & 392 & \multirow{2}{*}{0.708} \\
\hline & Rural & 62 & 1551 & \\
\hline \multirow{2}{*}{ Prior antibiotics } & Yes & 3 & 152 & \multirow{2}{*}{0.213} \\
\hline & No & 73 & 1791 & \\
\hline
\end{tabular}


Table 2. Underlying and associated conditions in bacterial meningitis in the studied population at University of Gondar Teaching Hospital, January 2011 - August 2013

\begin{tabular}{lcc}
\hline Clinical condition & Number & Percent \\
\hline Fever & 2000 & $(98.7 \%)$ \\
Headache & 1960 & $(97 \%)$ \\
Nausea & 1615 & $(80 \%)$ \\
Projectile vomiting & 1574 & $(78 \%)$ \\
Neck rigidity & 1635 & $(81.2 \%)$ \\
Consciousness & 791 & $(39.2 \%)$ \\
Seizures & 61 & $(3 \%)$ \\
Hypotension & 81 & $(4 \%)$ \\
Skin rash & 545 & $(27 \%)$ \\
\hline
\end{tabular}

Table 3. Correlation of smear and culture in bacterial meningitis in the studied population at University of Gondar Teaching Hospital. January 2011 - August 2013

\begin{tabular}{c|c|c|c|c}
\hline \multicolumn{2}{c|}{} & \multicolumn{2}{c|}{ Isolated organism } & \multirow{2}{*}{ Total } \\
\cline { 3 - 4 } \multicolumn{2}{c|}{ Gram stain } & positive & negative & \\
\hline \multirow{2}{*}{ Total } & 44 & 19 & 63 \\
& Neg & 32 & 1924 & 1956 \\
\hline \multicolumn{2}{c|}{} & $\mathbf{7 6}$ & $\mathbf{1 9 4 3}$ & $\mathbf{2 0 1 9}$ \\
\hline
\end{tabular}

Diagnosis of meningitis in the studied participant shows the correlation between smear and culture findings in patients with bacterial meningitidis. The bacterial pathogen could be demonstrated in gram stained smears of
63 (3.1\%) CSF samples, while CSF culture yielded positive growth in $76(3.8 \%)$ patients.

Bacterial pathogens were isolated from 76 patients showing an isolation rate of $3.8 \%$. No mixed bacterial infection was observed, the most frequent bacteria isolate were Streptococcus pneumoniae in 24 (31.6\%) isolate, Neisseria meningitidis in 14 (18.4\%) isolate, and Haemophilus influenzae isolated in $8(10.5 \%)$ isolate, Gram negative Bacilli 14 (18.4\%), followed by Gram positive coccie $14(18.4 \%)$ isolate, there were two isolate of Mycobacterium tuberculosis seen in pediatric age group.

Serotyping is done in 76 isolate $(3.8 \%)$. Serotype distribution of $S$. pneumoniae, Neisseria meningitidis and Haemophilus Influenzae causing meningitis in the South West part of Ethiopia is shown in [Table 5, Table 6, Table 7].

During in a 30 months period serotype distribution of $S$. pneumoniae involved as bacterial meningitis; serotype 1, (29.1\%), serotype 6, (16.6\%), serotype 14, (12.5\%), serotype $18 \mathrm{~F},(8.3 \%)$ serotypes $19 \mathrm{~F},(25 \%)$, serotype 20 , (8.3\%). Neisseria meningitides; serotype A (35.7\%)), serotype C, (21.4\%), serotype W-135 (35.7\%)) and One (7.1\%) nongroupable isolate of $N$. meningitdis are involved as bacterial meningitis. Eight cases of $H$. influenzae-associated meningitis were (serotype b, 7 cases; untypable, 1 cases).

The cell counts of the CSF samples ranged from no cells to sheets of cells, The mean sugar level in the CSF samples were tested was $22.3 \pm 9.8 \mathrm{mg} / \mathrm{dl}$, while a high mean level of protein $(85.3 \pm 51.29 \mathrm{mg} / \mathrm{dl})$ was detected in these samples. [Table 8].

Table 4. Etiology of acute bacterial meningitis by age group in the University of Gondar Hospital: January 2011 - August 2013

\begin{tabular}{|c|c|c|c|c|c|}
\hline \multirow{2}{*}{ Isolated bacteria } & \multicolumn{4}{|c|}{ Age } & \multirow{2}{*}{ Total } \\
\hline & 1-28day & 1-12 month & 1-11year & above 11 year & \\
\hline St. pneumoniae & 4 & 7 & 8 & 5 & 24 \\
\hline N. meningitides & 0 & 2 & 7 & 5 & 14 \\
\hline H. influenza & 2 & 4 & 2 & 0 & 8 \\
\hline Gram positive* & 1 & 1 & 3 & 9 & 14 \\
\hline Gram negative** & 1 & 1 & 4 & 8 & 14 \\
\hline M. tuberculosis & 1 & 0 & 1 & 0 & 2 \\
\hline Total & 9 & 15 & 25 & 27 & 76 \\
\hline
\end{tabular}

* All gram positive pathogenic bacteria other thane St. pneumoniae

** All gram negative pathogenic bacteria other than N. meningitides, and H. influenza.

Table 5. Serotype distribution of pneumococcal causing acute bacterial meningitis in the University of Gondar Hospital: January 2011 - August 2013

\begin{tabular}{c|c|c|c|c|c|c|c}
\hline Pneumococcal serotype & 1 & 6 & 14 & $18 \mathrm{~F}$ & $19 \mathrm{~F}$ & 20 \\
\hline Percent $(\%)$ & $(29.1 \%)$ & $(16.6 \%)$ & $(12.5 \%)$ & $(8.3 \%)$ & $(25 \%)$ & $(8.3 \%)$ & $24(100 \%)$ \\
\hline
\end{tabular}

Table 6. Serotype distribution of Neisseria meningitis causing acute bacterial meningitis in the University of Gondar Hospital: January 2011 - August 2013

\begin{tabular}{c|c|c|c|c|c|c}
\hline Neisseria meningitis serotype & A & C & W135 & X & NG & Total \\
\hline Percent $(\%)$ & $5(35.7 \%)$ & $3(21.4 \%)$ & $5(35.7 \%)$ & $(0 \%)$ & $1,(7.1 \%)$ & $14(100 \%)$ \\
\hline
\end{tabular}

Table 7. Serotype distribution of Haemophilus Influenza causing acute bacterial meningitis in the University of Gondar Hospital: January 2011 - August 2013

\begin{tabular}{c|c|c|c|c|c|c|c|c|c|c|}
\hline Haemophilus Influenza serotype & A & B & C & D & E & F & NG & Total \\
\hline Percent (\%) & 0 & $7(87.5 \%)$ & 0 & 0 & 0 & 0 & $1(12.5 \%)$ & $8(100 \%)$ \\
\hline
\end{tabular}


Table 8. Evaluation of the cytological and biochemical characteristics of the csf of the studied groups in the University of Gondar Hospital: January 2011 - August 2013

\begin{tabular}{l|c|c|c}
\hline Characteristics & N & Mean & p. value \\
\hline Positive group & & & \\
Number of cells (mm3) & 160 & 2505.49 & 7855.41 \\
Proteins (mg/dL) & 76 & 85.3 & 51.29 \\
Glucose (mg/dL) & 76 & 22.3 & 9.8 \\
\hline
\end{tabular}

\section{Discussion}

Acute bacterial meningitis is a medical emergency which deserves early diagnosis and aggressive therapy. Although the majority of cases with meningitis recover, it can cause serious complication, like brain damage, and deafness. It may even cause death unless the disease is treated successfully. Suitable diagnosis and antibiotic treatment of meningitis would reduce the risk of death from bacterial meningitis; however the risk remains high even among the elderly population. Using the recommended vaccines is the most effective way to protecting children and adults against bacterial meningitis caused by Streptococcus pneumoniae, Neisseria meningitidis, and Haemophilus influenzae [26]. However, limited information is available for the predominant serotype causing meningitis in northwest Ethiopia.

The final diagnosis of acute bacterial meningitides (ABM) depends upon a comprehensive analysis of CSF smears, culture, latex agglutination test (LAT), cytological, biochemical and clinical findings of the cases; a single test or parameter cannot be used as a benchmark to decide the course of management in the patient. However, empirical therapy is advocated, considering that a simple gram stained smear can present immediate indication to aid a diagnosis of bacterial meningitis as it has been reported by several workers [17]. In the present study, the examination of gram stained CSF smears helped in the diagnosis of ABM in $63(82.8 \%)$ cases. The yield of bacteria on gram staining depends on several factors, like the technique which is used for smear preparation, staining techniques and the observers' skills and experiences.

Though the common pathogens which are associated with acute bacterial meningitis are $S$. pneumoniae, $N$. meningitides, and $H$. influenzae, the etiological agents and their relative frequencies may vary in different geographical areas. Changing trends in the epidemiology of ABM are being observed and reported worldwide. In our study the majority of the patients $(86.8 \%)$ were adults, while only $13.2 \%$ patients were from the paediatric age group. A similar finding reported from India [19]. Males were found to suffer from bacterial meningitides 1.37 times more frequently than females. Studies in Teheran [17], a previous work in Gondar, Ethiopia [18], and a research conducted in India [19] reported similar findings. Serotype which are most commonly associated with bacterial meningitis in all age groups were streptococcus pneumoniae (31.6\%), Neisseria meningitidis (18.4\%), and Haemophilus influenzae (10.5\%), gram positive bacteria (18.4\%) and gram negative rod (18.4\%); a similar trend was reported from India [19]. No bacterial pathogen was identified in $96.8 \%$ of the meningitis cases although Streptococcus pneumoniae is the predominate pathogen of meningitis.
In this study, 76 patients were diagnosed with bacterial meningitis. The most frequent bacteria isolated were $S$. pneumoniae (31.6\%), a finding similar with that of a previous research in Gondar [20]. However, a frequency of $43.3 \%$ for Streptococcu pneumoniae in CSF samples of meningitis patients were reported by a previous study in Gondar [20] The rationale for this reduced rate could be the variation in their vaccination programs.

Nowadays there are more than 94 types of pneumococcal bacteria; presently three PCV vaccines available on the overall market are Prevnar (PCV-7), Synflorix (PCV-10), and Prevnar 13 (PCV- 13). The pneumococcal conjugate vaccine (PCV7) protects against 7 strains, namely 4, 6B, 9V, 14, 18C, 19F, and 23F. These bacteria types are responsible for the most common severe pneumococcal infections among children (22). The 10 pneumococcal serotypes which the PCV-10 vaccine contains are 1, 4, 5, 6B, 7F, 9V, 14, 18C, 19F, and 23F. Each of these is conjugated to a carrier protein. PCV-13 is a tridecavalent vaccine, which is it contains thirteen serotypes of pneumococcal, namely $1,3,4,5,6 \mathrm{~A}, 6 \mathrm{~B}, 7 \mathrm{~F}$, $9 \mathrm{~V}, 14,18 \mathrm{C}, 19 \mathrm{~A}, 19 \mathrm{~F}, 23 \mathrm{~F}$ these also conjugated to a carrier protein [21]. Previous reports suggested that $S$. pneumoniae N.meningitidis and Haemophilus influenzae were the most common bacteria causing acute bacterial meningitis in Ethiopia [12,18,20]. The most detected serotypes in our study were $1: 29.1 \%$ and then $14: 12.5 \%$, 19F: $25 \%$ which are included in PCV10 vaccintion, which cover $65 \%$ of the total serotype.

$N$. meningitidis were found to be the second cause of bacterial meningitis. In this study, isolation rate from csf was $14(18.4 \%)$; out of these $13(17.1 \%)$ patients were less than 11 years of age, Only one $N$. meningitidis was isolated from patients greeter than 11 years old. This suggests that the incidence of meningitis increase at ages prior to the lunching of vaccination programs. This was in contrast with the low incidence reported by other Indian studies [19]. But surprisingly, the highest rate of meningitis is reported among 7-11 year old males. The most detected serotypes in our study were A: $5,(35.7 \%), C: 3,(21.4 \%)$, $\mathrm{W}-135$ : 5 , (35.7\%), and 1, (7.1\%) nongroupable isolate were involved as $N$. meningitidis.

In this study, $N$. meningitidis, especially serogroup A, $35.7 \%$ was responsible for most of the cases observed, with serogroup $\mathrm{W}-135$ : $35.7 \%$. Only a small number (21.4\%) of serogroup $\mathrm{C}$ cases were noted, and no serogroup B and $\mathrm{Y}$ cases were observed. These data are similar to those reported from many parts of Africa where serogroups A and $\mathrm{C}$ dominate the epidemiologic landscape. In Gondar, a meningococcal disease caused by serogroup W-135 isolated two cases in 2011 and three cases in 2012. Therefore, the rise in the proportion of cases caused by serogroup W-135 may be attributable to transmission by pilgrims returning from the Hajj carrying this particular 
serogroup. Epidemiologic investigations will be required to support this hypothesis.

The choice of meningococcal conjugate vaccines in Ethiopia will need to include coverage for serogroup W135; the introduction of such a vaccine would be helpful in protecting Ethiopians from this invasive bacterial meningitis. Moreover, it may also be prudent to switch the meningococcal vaccine used for pilgrims to a conjugated vaccine in order to prevent the carriage of the microorganism by pilgrims.

According to these data, only serotype $b$ of Haemophilus influenzae is involved in bacterial meningitis. Eight cases of $H$. influenzae-associated meningitis namely serotype b, 7 cases and untypable, 1 case were recorded. This serotype is one of the main causes of meningitis in children 1 to 60 months in our country.

One case of Group B Streptococcus and one case of Listeria monocytogenes are also being recognized as an important causes of meningitis in neonates in the this study. The finding is in line with that of a research done in USA [23].

As compared to what is seen in Western studies [23,24], the relative incidence of meningitis which is caused by Listeria is less common in Ethiopia. On the contrary, Gram negative bacilli, such as E.coli, Salmonella, Klebsiella ozanie, Klebsiella pneumonia, Proteus voligarus and Pseudomonas aeruginosa are being recognized as important causes of meningitis, especially among the elderly group $[19,20]$. Among the gram positive coccie, staphylococci auras is the most common pathogen associated with meningitis in all age groups.

\section{Conclusions}

Generally, the isolation rate of bacteria causing meningitis is low. This may probably be due to the fastidious nature of the organism prior exposure to antibiotics or over a clinical diagnosis of meningitis, but unusual findings and a high proportion of serogroup W135 meningococci are observed in our study area. The role of clinical presentations, routine CSF analysis in the rapid diagnosis of acute bacterial meningitis in cases of negative gram stained smears and a good knowledge of the bacterial epidemiology of meningitis can serve as guides to start a rapid treatment as early as possible without waiting for culture results available in suspected cases of bacterial meningitis to overcome the lethal complications.

\section{Limitations of the Study}

The isolation rate of bacteria causing meningitis was low and the process was conducted at only one centre. Future studies should be prospective, multicentre casebased, and laboratory confirmed.

\section{Recommendation}

The high proportion of serogroup W-135 meningococcal observed in our study area is cause for concern and this situation is suboptimal and calls for the development of affordable, multivalent conjugate vaccines against serogroups $\mathrm{A}, \mathrm{C}, \mathrm{Y}, \mathrm{W}$, and $\mathrm{X}$ meningococcal. And highlights the need to have a multicentre of case based, laboratory confirmed surveillance of bacterial meningitis across the country and determine the potential effects of existing vaccines.

\section{Conflict of Interests}

The authors declare that there is no conflict of interests regarding the publication of this paper.

\section{Acknowledgments}

The authors acknowledge to the study participants, Gonder university hospital staff members for their assistance during patient recruitment and inclusion, Linet Desmaretz for assistance for stereotyping of the isolate. This research was supported partly by University of Gondar Hospital and partially by Institute of tropical medicine in Belgium.

\section{References}

[1] Prober CG. Central Nervous System Infections. In: Nelson's Textbook of Pediatrics 18th edition. Kliegman RM, Behrman RE, Jenson HB, Stanton BF editors, Elsevier, New Delhi 2008; 2512-21.

[2] Scheld WM, Koedel U, Nathan B, Pfister HW. athophysiology of bacterial meningitis: mechanism(s) of neuronal injury. J Infect Dis 2002; 186 (2): 225-233.

[3] Osrin D, Vergnano $S$, Costello A. Serious bacterial infections in newborn infants in developing countries. Curr Opin Infect Dis 2004; 17: 217-224.

[4] Grimwood K, Anderson VA, Bond L, Catroppa C, Hore RL, Keir $E H$, et al. Adverse outcomes of bacterial meningitis in school-age survivors. Pediatrics 1995; 95:646-656.

[5] World Health Organization. Control of epidemic meningococcal diseases. WHO Practical Guidelines.2 ed. 1998. Geneva Switzerland.

[6] Puopolo KM. acterial and fungal infections.In Manual of Neonatal care 4thed. Cloherty JP, Eichenwald EC, StarkAR editors Lippincott- Raven, Philadelphia 2008: 274-93.

[7] Solberg C.O. Meningococcal infections, In Fauci A.S., Braunwald E, Isselbacher K.J, et al (eds.), Harrison's principles of internal medicine, 14th ed. McGraw- Hill, New York USA 1998; 9: 910-15.

[8] WHO (2012). Bacterial meningitis. www.who.int/nuvi/ meningitis.

[9] Tunkel AR. Clinical Trials Report. Curr Infect Dis Rep 2001; 3:347-351.

[10] Mengistu G., Mitiku K., Teferi W., (2003). Analysis and reporting of meningococcal meningitis epidemic in north Gondar. Ethiopia Medical Journal.; 41(4): 319-31.

[11] Laving AM, Musoke RN, Wasunna AO, Revathi G. Neonatal bacterial meningitis at the newborn unit of Kenyatta National Hospital. East Afr Med J 2003; 80:456-462.

[12] Norheim G., Rosenqvist E., Assefa A., et al, (2006). Nesseria meningitis isolated from recent out breaks in Ethiopia and comparison with those Recovered during the epidemic of 1988 to 1989. Jornal of clinical microbiology. 44:861-871.

[13] Brooks G, Caroll K, Butel J, Morse SA, Mietzner TA. Jawetz Melnick \& Adelbergs Medical Microbiology 26/E edn.The McGraw-Hill Companies, Inc. N.Y 2013.

[14] Clinical and Laboratory Standards Institute. Performance standards for antimicrobial susceptibility testing. 16th informational supplement (M100-S16). Wayne, PA: CLSI, 2006.

[15] Bauer AW, Kirby WMM, Sherris JC, Turck M. Antibiotics susceptibility testing by a standardised single disc method. $A m J$ Clin Pathol 1966; 45: 493-6. 
[16] National Committee for Clinical Laboratory Standards. Performance standards for antimicrobial disk susceptibility test, 7th ed. Approved standards, NCCLS Document.

[17] Mohammad M, Abdolreza G, Mirkaveh M, Noushin D Identification of the serotypes of bacterial meningitis agents; implication for vaccine usage Iranian journal of microbiology; Volume 6 Number 4 (August 2014) 211-218.

[18] Andargachew M, Afework K, Belay T, Bacterial isolates from cerebrospinal fluids and their antibiotic susceptibility patterns in Gondar University Teaching Hospital, Northwest Ethiopia; Ethiop.J.Health Dev. 2005; 19(2)

[19] Syamal M., Amit Kumar A., Phenotypic Characterization and antibiogram of CSF Isolates in Acute Bacterial Meningitis; Journal of Clinical and Diagnostic Research. 2013 Dec, Vol-7(12): 2704-2708.

[20] Birhanemeskel T, Solomon G, Nigus F Bacterial Meningitis: a five-year retrospective study among patients who had attended at University of Gondar Teaching Hospital, Northwest Ethiopia. Journal of Biomedical Research and Therapy 2015, 2(5): 270-278.

[21] Miller E, Andrews NJ, Waight PA, Slack MP, George RC. Effectiveness of the new serotypes in the 13-valent pneumococcal conjugate vaccine. Vaccine; 29:9127- 9131.
[22] Hsu HE, Shutt KA, Moore MR, Beall BW, Bennett NM, Craig AS, et al. Effect of pneumococcal conjugate vaccine on pneumococcal meningitis. N Engl J Med 2009; 360:244-256.

[23] Schuchat A, Robinson K, Wenger JD, Harrison LH, Farley M, Reingold AL, Lefkowitz L, Perkins BA. Bacterial meningitis in the United States in 1995. Active Surveillance Team. N Eng J Med 1997; 337: 970-76.

[24] Rabab F, Marwa K, Waleed F, Taha G, et al. Role of Clinical Presentations and Routine CSF Analysis in the Rapid Diagnosis of Acute Bacterial Meningitis in Cases of Negative Gram Stained Smears, Journal of Tropical Medicine Volume 2014, Article ID 213762, 7 pages.

[25] Lund E, Henrichsen J. Laboratory diagnosis, serology and epidemiology of Streptococcus pneumoniae. Methods Microbiol 1978; 12: 241-262.

[26] Davis S, Feikin D, Johnson HL. The effect of Haemophilus influenzae type $\mathrm{B}$ and pneumococcal conjugate vaccines on childhood meningitis mortality: a systematic review. BMC Public Health 2013; 13 Suppl 3: S21. 